ECCOMAS Proceedia
COMPDYN 2017

$6^{\text {th }}$ ECCOMAS Thematic Conference on Computational Methods in Structural Dynamics and Earthquake Engineering

M. Papadrakakis, M. Fragiadakis (eds.) Rhodes Island, Greece, 15-17 June 2017

\title{
SENSITIVITY OF STRUCTURES AND GEOLOGICAL DATA
}

\author{
V.A. Barvashov ${ }^{1}$, G.G.Boldyrev ${ }^{2}$ \\ ${ }^{1}$ NITs "Stroytelstvo" Inc., NIIOSP \\ barvash@mail.ru \\ ${ }^{2}$ Penza state university architecture and construction \\ g-boldyrev@geoteck.ru
}

Keywords: Subgrade-structure sensitivity, Geological data, In situ tests, Subsoil stiffness factor, Numerical simulation, Soil data uncertainties.

Abstract. The paper discusses the subgrade-structure sensitivity to uncertainties, ambiguities
and scarcity of geological data, obtained and processed in the course of geological surveys.
These aspects have mostly been neglected: two special in situ tests, staged in USA and in Rus-
sia, showed considerable soil data uncertainties and scatter even at nearby points. On the
other hand, most structures are insensitive to many (not all) these uncertainties. So, a com-
promise between structure sensitivity and soil data uncertainties is an issue. Numerical simu-
lation with the help of specially developed software showed some sensitivity evaluation results.

C 2017 The Authors. Published by Eccomas Proceedia.

Peer-review under responsibility of the organizing committee of COMPDYN 2017.

doi: $10.7712 / 120117.5749 .17068$ 


\section{INTRODUCTION}

The Conference guidelines are in tune with coincide the issues of geotechnical engineering: i.e. uncertainty, ambiguity and scarcity of on-site geological survey data along with multiple and diverse subsoil-structure system (SSS) interaction theories and analytical methods. Theoretical models and assumptions for solving geotechnical problems are too many. Finite elements method (FEM) enables detailed numerical simulations of SSS behavior; however, the input soil data and their scatter are insufficient and often dubious. E.g., the subsoil test holes are spaced at least $25 \mathrm{~m}$ from each other, and they are very few. Why do the built structures stay healthy for centuries despite of such input soil data scarcity? There is only one realistic explanation to this: the real SSSs are very insensitive to the errors and scarcity of input soil data and to the diversities of many analytical assumptions and theories. The paper presents examples of soil data uncertainties and SSS analysis deficiencies, based on in situ and smallscale model test data and some numerical simulations.

\section{SPECIFIC FEATURES OF SSS GEOTECHNICAL ANALYSES}

Any SSS project design involves only one numeric analysis. Multiple numeric simulations are very rare. This is not so in other sectors. E.g., automobiles, aircraft, spacecraft and their components, etc. are subjected to physical and numerical tests and simulations. The material strength, deformations, ageing, etc. are thoroughly tested, and the test data is stored in databases along with many numeric and real scenarios for handling possible contingencies. These research and development involves multiple numeric and physical simulations on real models, including full-scale ones, the data is stored in databases along with various numeric and real scenarios of future contingencies and respective countermeasures.

It is not so in the building construction sector. Monitoring the settlements of existing structures just prove their existence, which is evident anyway, while stresses in structural elements can only be measured at a very limited number of accessible points. The real contingencies and failures are extremely rare and are mostly due to human error and/or contingencies.

The soil data, investigated for any project design is scarce: the total tested soil volume on any site is literally infinitesimal: only millionth parts $\left(10^{-6}, \mathrm{ppm}\right)$ of the total volume of subsoil are tested and sampled in just a few test holes, located more than $20 \mathrm{~m}$ and farther apart from each other. Soil properties between test holes remain practically uncertain even if investigated with a geo radar. After in situ tests are over, the geologists produce several vertical subsoil cross sections with subjectively "inflated" soil stratification between widely spaced test holes. The geologists also subjectively (i.e. ambiguously, creatively) delineate stratigraphic geotechnical elements (GEs) in several cross sections wrongly assigning identical properties to soils in each GE. Then design engineers creatively inflate the soil properties in-between these cross sections. Therefore, there is always a rather large space for doubt as how realistic these subjective results could be. There is no other choice, however, because geological investigations (GI) costs are traditionally low: just $0,05-0,1 \%$ of the total construction cost. A question arises: how effective are these low costs at the global scale in comparison to safety?

Soil mechanics and SSS geotechnical analyses appeared long ago based on very simplified assumptions and analyses. E.g., homogeneous elastic solutions prevailed in soil mechanics for many decades. Then dozens of non-linear soil continuum models appeared and some of them entered Finite Elements Method (FEM) computer codes (PLAXIS and MIDAS prevail in Russia now). However, due to uncertainties of soil data the reality of such FEM analytical results remains uncertain. The scarce soil data from several GI test holes is insufficient for input in FEM computer codes. Therefore, GI data is inflated in the form of virtual strata and geotechnical elements to sort of "make up" for the soil data scarcity. These procedures look very 
realistic, as the relative contingency rate due to subsoil failures is very small $(\approx 0,01 \%)$. Just compare it with more than $2 \%$ failure rate of spacecraft launches.

Geotechnical engineers do not practically investigate how realistic, unambiguous and sufficient GI data are, obtained in situ or in laboratory tests for SSS project designs. The authors are aware of just two following experiments, specially staged to investigate the uncertainty of soil data measurements.

\subsection{Experiment 1}

The Louisiana State University (USA) performed experimental CPTs (Cone Penetration Tests) on an ordinary site, following the request from USA Federal Highway Administration [1]. The tests were performed at 16 points, located along two concentric circles, having 0.9 and $1.8 \mathrm{~m}$ radii, with one test point in the center. There were measured cone resistance $q_{c}$ and soil unit weight $\gamma$ values versus depth. The obtained data showed that the soils were very nonhomogeneous both vertically and horizontally, therefore the homogeneous strata that all geologists so creatively delineate on geological cross sections are subjective, i.e. and non-realistic.

\subsection{Experiment 2}

A similar experiment was done in Russia (NPP Geotek, Russia) with the help of the famous Marchetti dilatometer (Fig. 1).

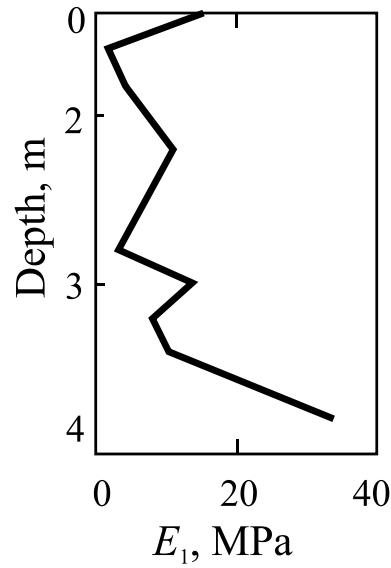

a)

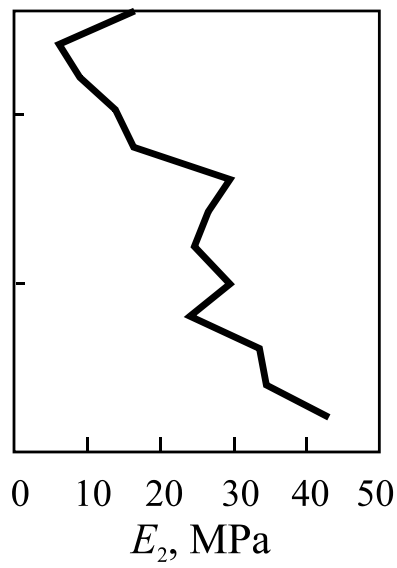

b)

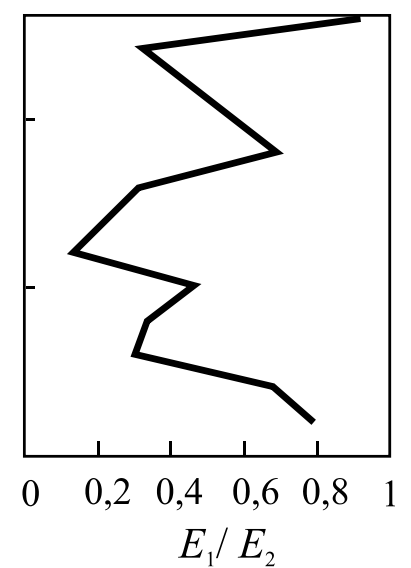

c)

Figure 1: Soil moduli $E_{1}$ and $E_{2}$ profiles, measured with Marchetti dilatometer in test holes a) $E_{1}$ and b) $E_{2}$, spaced at $2 \mathrm{~m}$ from each other and c) $E_{1} / E_{2}$ ratio.

Fig. 1 shows the measured deformation modules $E_{1}$ and $E_{2}$ profiles (Figs. 1a, b) and their ratio $E_{1} / E_{2}$ variations versus depth (Fig. 1c) in two test holes, located $2 \mathrm{~m}$ apart from each other. Evidently, $E_{1} / E_{2}$ values are far from being equal to 1 .

A question arises, is it worthwhile to complicate geotechnical analyses if the detailed and consistent GI soil data for such analysis is never available? If data scatter is such then simplified SSS analyses could successfully compete with sophisticated and highly expensive FEM software capabilities.

Geological investigations include other test types beside CPT and dilatometer: plate tests, SPT, dynamic penetration tests, boring penetration tests etc. The obtained results are processed with the help known correlation equations to obtain data for project design analysis. However, despite of inevitable data scatter and ambiguities: only one test is done at each point. 
The authors do not have information of any other similar soil tests at close distances except for the ones presented on Figs. 1.

There is one optimistic aspect, worth mentioning. In a SSS settlement analysis soil deformations (always positive) are summed up/integrated versus depth. This integration transformans forms rough deformations profiles into rather smooth settlements-versus-depth curve, as is shown on Fig. 2, where such transformation. a strongly oscillating function $s=s(x) \geq 0$ (red) is integrated to obtain function $S(x)$ as per Eq. (1). This integration produces a rather smoothly growing function $S(x)$ (blue curve)

$$
S(x)=\int_{0}^{x} s(x) d x
$$

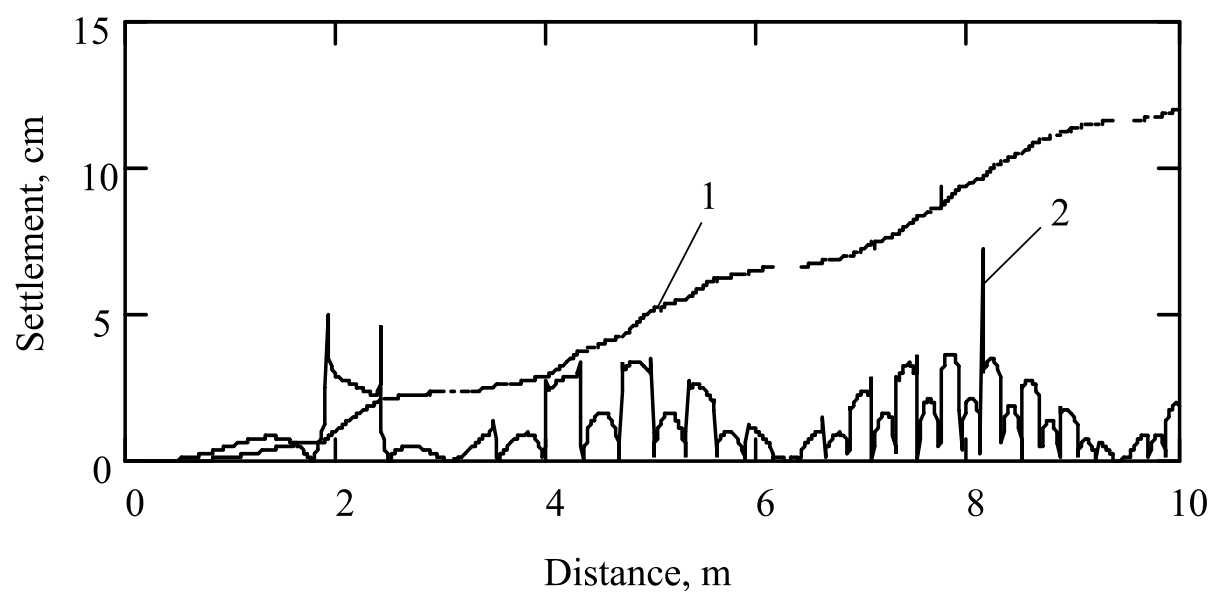

Figure 2: An example of smoothing a strongly oscillating function by integration: 1 - smoothing; 2 - oscillation.

\section{CONTACT MODELS OF SUBSOIL}

Thanks to "smoothing", shown on Fig.6, it is possible to apply linearly deforming subsoil contact models (CM) to subsoil analysis. Many authors proposed different CMs, each of which features unique properties, defined by its Green function, some of them coincide with each other despite of their different physical representation. The Green function gives the respective subsoil surface settlement at a point, caused by a unit vertical force, applied at distance $r$ from that point. Surface settlements under distributed load $q(x, y)$ are determined by evident integration. Green functions are defined for many CMs, including Winkler (delta function) and Pasternak CMs, elastic space, elastic layer, etc.

Hundreds of publications, including doctorate theses, books and conference proceedings, are dedicated to to CMs' applications in the subsoil settlements analysis. CMs are included in Russian Geotechnical Codes of Practice for subsoil and footing design.

CMs are applied to settlement analysis of non-uniform subsoils with just one assumption that vertical normal stresses $\sigma_{z}$ from any vertical load, distributed over the subgrade surface, coincide versus depth for uniform and layered subgrades. However not well proved, this assumption is globally applied to CM-based settlement analyses with defined Green functions.

Green functions application have their own paradoxes in exact analytical solutions, e.g. infinite contact pressures under a stiff footing edges on elastic half-space. A layer of Winkler springs on top of such CM corrects the situation 


\section{FINITE ELEMENTS METHOD}

FEM gives numerical solutions for the problems of non-linear continuum mechanics with complicated configurations, any boundary conditions and heterogeneities, etc. However, these possibilities are often excessive when applied to practical problems, whose solutions depend on GI ever scarce and uncertain soil data. But there is a good chance that numerical FEM simulation modelling could replace difficult material experiments, especially qualitative ones.

There is also on more issue: PLAXIS and MIDAS do not account for discontinuities of soil media, caused by shear stresses, that results in ambiguity of analytical results, because they depend on the FEM grid density, i.e. on the dimensions of finite elements (see below).

\section{SUBSOIL DEFORMATIONS AND STRENGTH}

The problems of subsoil bearing capacity (strength) have been solved with the help of limit equilibrium theory Terzaghi [2] and Sokolovsky [3] have been solved since 1940s. This theory assumes that subsoil failure process is static, i.e. occurs simultaneously at all points of the limit equilibrium zone. These solutions were developed for homogeneous subsoils.

In fact, after the load is applied the soil first reaches limit state at points under the footing edges. If the load keeps on increasing, then downward cracks appear and grow downwards with rupture points at their lowermost ends that result in excessive tilts of the structure. This subsoil kinematic condition is reached at much lower external load than the abstract limit load that causes the simultaneous abstract static subsoil failure at all points of the limit equilibrium zone as per Terzaghi [2] and Sokolovsky [3]. It is more justified to view the load, creating "inadmissible" structure tilts well before the total subsoil failure.

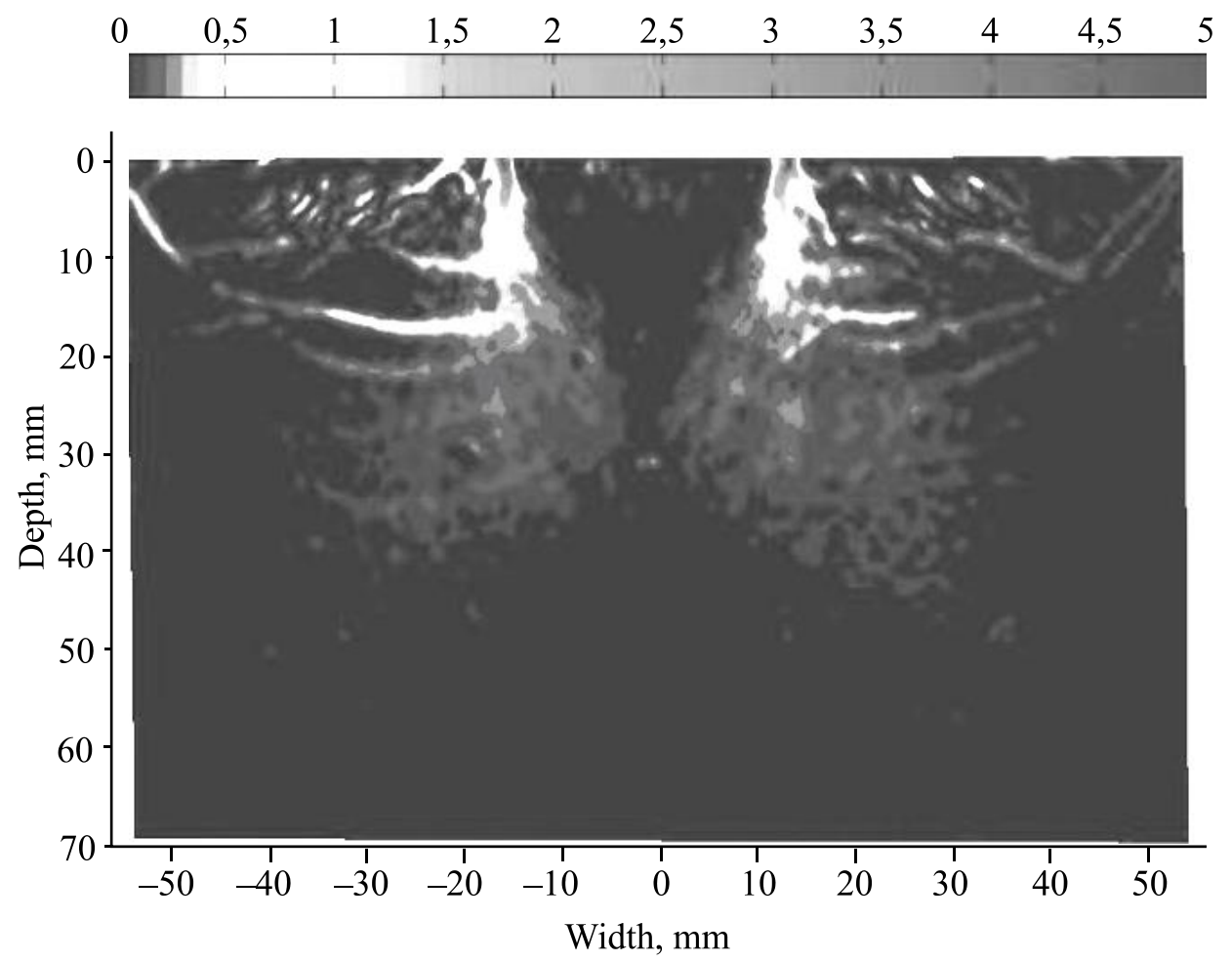

Figure 3: Formation of "cuts" (against the light) under the model footing edges. The scale indicates the intensity of shear strain, $\%$. White color is tension cracks 
Fig. 3 shows soil tension cracks ("cuts") under the edges of a vertically loaded small footing model on clay in a test box. Tests were carried out by the method of digital processing of images. These "cuts" result from a typical progressive (kinematic) failure. It is principally different from instantaneous (static) failure, i.e. collapse, assumed in solutions by Terzaghi [2] and Sokolovsky [3], which occurs simultaneously within the abstract limit equilibrium zones. This photo shows that "cuts" rather than limit equilibrium zones form up under footings before the footing failure.

The same "cuts" appear under footing edges as result of footing-subsoil FEM analysis with FEM simulated shear cuts due to shear modulus degradation and tension cracks, without it analytical values of tilts and bending moments in footings are distorted

\subsection{Subsoil heterogeneity as per GI data by Shepard approximation}

As was indicated above, geologists believe that they can manually restore (inflate) subsoil stratification, although two geologists would produce different pictures. It can be done in even greater detail with the help of Shepard approximation. But whatever is the inflation it is always ambiguous and fictitious.

\subsection{Qualitative analysis of SSS virtual behavior}

Physical simulations of contingencies and failures of full-size structures is practically impossible. Numerical computer simulations are much more effective and yield ample data to identify and to assess qualitative effects. Below are given two such cases, linked up with "cut" formation.

1. Concentration of contact stresses under footing edges (Fig. 4) in the cases of "cut" absence (unlimited) contact stresses under edges and "cut" formation under the edges (limited contact stresses).

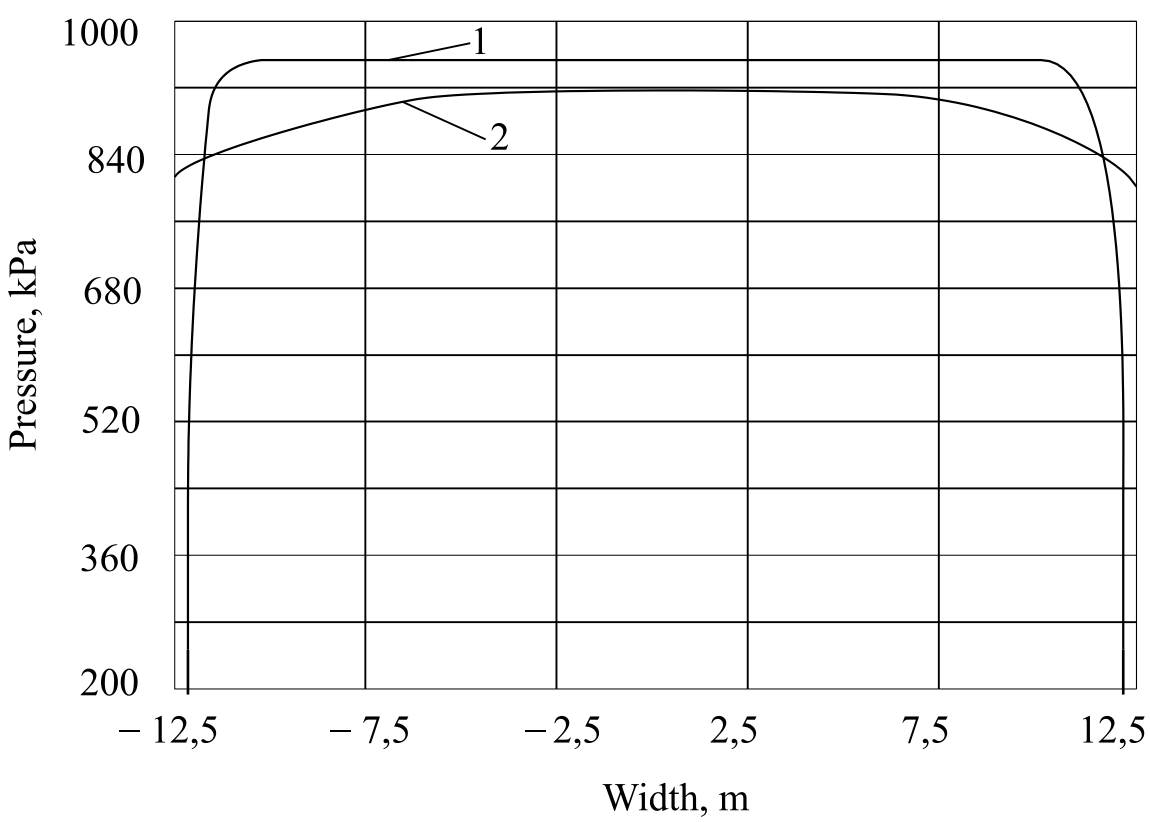

Figure 4: Side contact stresses without and with "cut" taken into account under footing edges: 1 - unlimited contact stresses; 2 - limited contact stresses 
"Cut" formation under footing edges is inevitable, because otherwise theoretical solutions give infinite contact pressures under footing edges. A "cut" straightens the stresses under the footing and transforms their distribution to practically uniform. These transformations change the distribution of bending moments.

2. Growth and tilts of a symmetrically loaded structure if soil strength ( $c$ and $\varphi$ values) is different under footing edges.

Numeric simulations showed that a structure can "rock" in the process of erection if the load is symmetric and the soil strength parameters under opposite edges are different. The tilts may firstly grow and then change directions in the process of the building erection (Fig. 5). It is a sort of "rocking" from side to side.

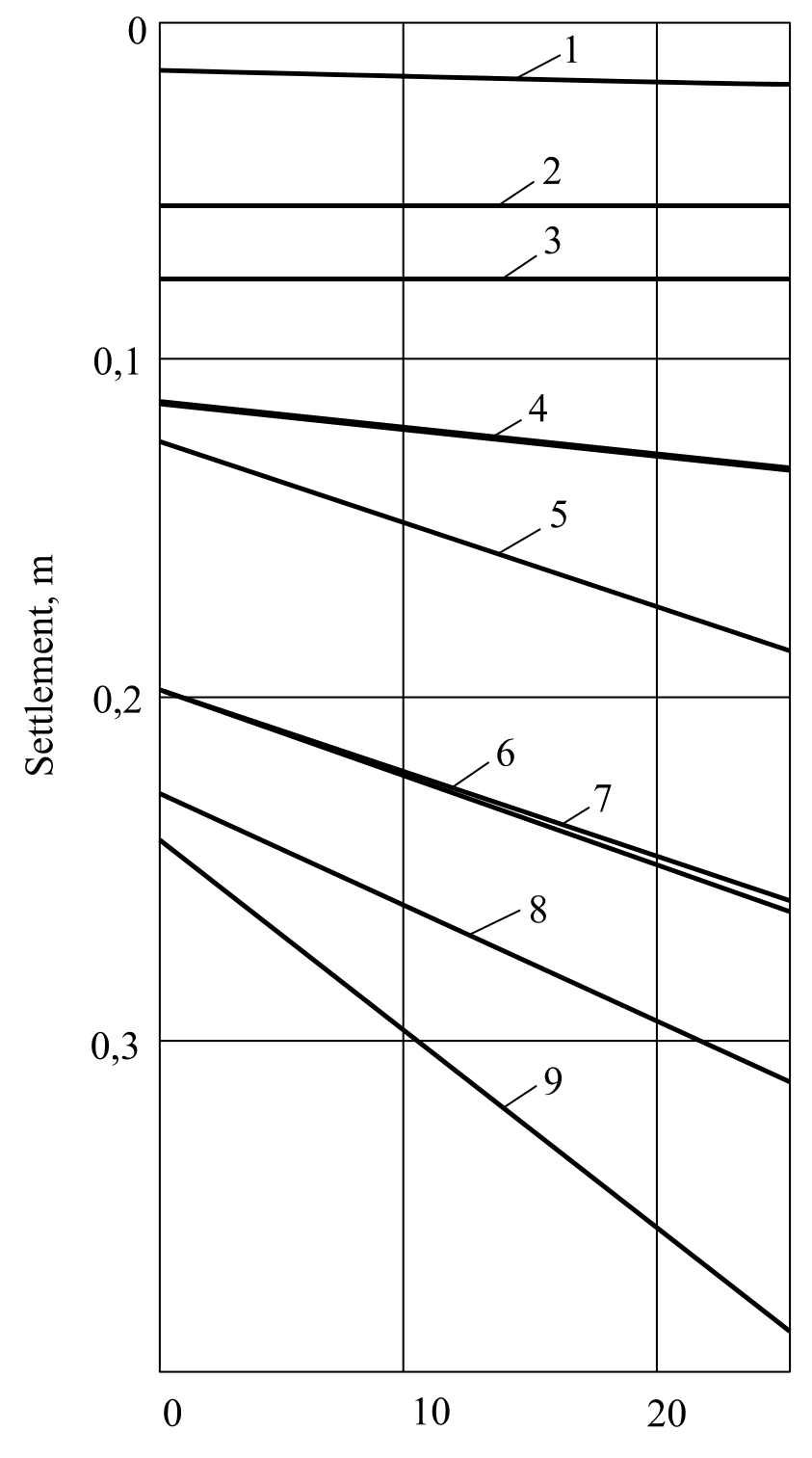

Width the plate, $m$

Figure 5: Growth of tilts erected buildings $25 \mathrm{~m}$ width:

$1-9$ - settlement left and right edges of the plate at different loads

(in ascending order of load from 0 to $0.5 \mathrm{MPa}$ ). 
The tilts "straighten" at the last stage although the structure rocks from side to side during erection. But such "rocking" can be progressive: it is a critical state as per Eurocode 7.

The above numeric examples show that random inflation of GI data and ignorance of various factors (e.g. different soil strength under footing edges) can result in unpredictable situations and contingencies.

\section{SETTLEMENT ANALYSIS WITHOUT "INFLATING" GI DATA}

During GI the most reliable soil data are measured in the test holes, and this very data (no more) shall be applied in the analysis without any subjective "inflation" over the whole volume of subsoil. Two commonly applied assumptions shall be used to carry out settlement analysis.

\section{$1^{\text {st }}$ assumption}

Distribution of vertical normal stresses $\sigma_{z}=\sigma_{z}(x, y, z)$ under any footing along any vertical line under it does not depend on the subsoil inhomogeneity.

In the case of shallow rock $\sigma_{z}=q=$ const, wih $q$ as mean structure-subsoil pressure.

\section{$2^{\text {nd }}$ assumption}

Within the "cut" depth under footing vertical normal stresses $\sigma_{z}$ in soil under footing are constant. This assumption is both realistic and necessary because otherwise infinite footingsoil contact stresses would appear that would make the analysis impossible.

Apply a uniformly distributed load q, equal to the mean structure-subsoil contact pressure. Subsoil settlement $s_{i}=s\left(x_{i}, y_{i}\right)$ at the location of the $i$-th test hole with $x_{i}, y_{i}$ coordinates is computed by integrating vertical deformations $\varepsilon_{\mathrm{zi}}=\varepsilon_{z}\left(x_{i}, y_{i}, z\right)$, caused by stresses $\sigma_{\mathrm{zi}}=\sigma_{z}\left(x_{i}, y_{i}, z\right)$ along the depth of compressible layer $H_{i}$ :

$$
s_{i}=\int_{0}^{H} \varepsilon_{i} d x=\int_{0}^{H_{i}} \frac{\sigma_{z i} d z}{E\left(x_{i}, y_{i}, z_{i}\right)}
$$

with $i=1 \ldots . . N$, and $N$ as test holes number on the site.

Then subsoil stiffness factor $(K)$ at $i$-th point $\left(x_{i,} y_{i}\right)$ :

$$
K_{i}=K\left(x_{i}, y_{i}\right)=\frac{q}{s_{i}} .
$$

$K$ - values for points under the footing edges should involve formation of the "cut" to avoid non-existent singularities. Many existing methods of footing-structure analysis do not "see" this singularity, e.g. Boussinesq [4] and Schleicher [5] exact mathematical solutions for stiff plate on elastic half-space or half-plane.

The obtained values of all $K_{i}$ could be extrapolated over the whole surface of the subsoil under the structure. E.g., it can be done with the help of Shepard [6] technique:

$$
W(x, y, n, N)=\frac{\sum_{i=0}^{N} \frac{K_{i}}{\left[\left(x-X Y_{i, 1}\right)^{2}+\left(y-X Y_{i, 2}\right)^{2}\right]^{n}+0,001}}{\sum_{i=1}^{N} \frac{1}{\left[\left(x-X Y_{i, 1}\right)^{2}+\left(y-X Y_{i, 2}\right)^{2}\right]^{n}+0,001}},
$$

with $n$ as free approximation surface shape parameter to simulate uncertainty of soil data from test holes, $N$ as number of test holes, $X, Y$ as $(x, y)$ coordinates array: $X Y_{i, 0}=x_{i}, X Y_{i, 1}=y_{i}$. 
The value 0,001 is introduced to smooth removable discontinuities in Eq. (4) at locations of test holes.

Then the system three equations of static equilibrium can be compiled:

$$
G s=F,
$$

with $G\left(I_{i, j}\right)$ as square $3^{\text {rd }}$ order matrix of the system linear equations (5) with:

$$
\begin{gathered}
I_{i, j}=\int_{0}^{L} \int_{0}^{B} W(x, y, n, N) x^{i} y^{i} d y d x, \\
F=\left(\begin{array}{l}
Q \cdot \frac{L}{2} \\
Q \cdot \frac{B}{2} \\
Q
\end{array}\right) .
\end{gathered}
$$

with $Q$ as resultant of vertical loads, applied to the structure, including its proper weight; $L$ as length and $B$ as width of the structure.

Hence:

$$
s=G^{-1} F,
$$

with $G^{-1}$ as inverse matrix. Wherefrom:

$$
s=\left(\begin{array}{l}
\alpha \\
\beta \\
S
\end{array}\right) .
$$

with $\alpha, \beta$ as tilts versus $O y, O x$ axes respectively; $S$ as their structure settlement at point $(0,5 L, 0,5 B)$. Or $s(x, y)=\alpha x+\beta y+S$, with coordinate $x$ and $y$ versus geometrical SSS center $S$ as settlement of SSS geometrical center.

\subsection{Settlement analysis of a 40x20 m SSS}

Two virtual cases have been analyzed: with 5 test holes (located at the corners and in the center of a would-be rectangular structure) and 9 test holes $(5+4$ holes at the centers of rectangle side). The mean (uniform) pressure from the structure on subsoil $q=0,3$ МПа. $E, c, \varphi$ values of the soil parameters with vertical distributions in test holes were assigned randomly with the help of random numbers generator.

The obtained results are presented below as columns with three values each as per (9): two tilts $\alpha, \beta$ and one mean settlement $S_{\text {mean }}$ values. The uncertainty of these results between boreholes was simulated by parameter $n$.

\begin{tabular}{|c|c|c|c|c|}
\hline & $n=1$ & $n=2$ & $n=3$ & $n=4$ \\
\hline$\alpha$ & $-0,00191$ & $-0,00244$ & $-0,00255$ & $-0,00258$ \\
\hline$\beta$ & $-0,00365$ & $-0,00552$ & $-0,00604$ & $-0,00620$ \\
\hline$S_{\text {mean }}, \mathrm{cm}$ & 0,18752 & 0,22895 & 0,23946 & 0,24288 \\
\hline
\end{tabular}

Table 1: Results by number boreholes $N=9$ 


\begin{tabular}{|c|c|c|c|c|}
\hline & $n=1$ & $n=2$ & $n=3$ & $n=4$ \\
\hline$\alpha$ & $-0,00322$ & $-0,00375$ & $-0,00384$ & $-0,00388$ \\
\hline$\beta$ & $-0,00079$ & $-0,00113$ & $-0,00122$ & $-0,00124$ \\
\hline$S_{\text {mean }}, \mathrm{cm}$ & 0,22406 & 0,23376 & 0,23457 & 0,23481 \\
\hline
\end{tabular}

Table 2: Results by number boreholes $N=5$

In order to evaluate possible output scatter four cases with $n=1,2,3,4$ were computed, $n=1$ is least realistic, calculated for comparison with the more "realistic" values. In both cases $(N=5$ and $N=9)$ the settlements are almost identical with $\approx 1 \%$ accuracy except $n=1$. The calculated tilts for $N=9$ are $\approx 4-5$ times greater than for $N=5$ and changed the sign from plus to minus. So whatever are $N=9$ the representative value.

This the brief description of the new GI approach that is being developed in NPP Geotek (Russia, Penza) now. It will enable on-line GI data processing during GI to identify the representative number of test holes is and to be chosen correct values of analytical settlements and tilts. It will also yield $\mathrm{E}, \mathrm{c}$ and $\varphi$ values distribution for further SSS computer analysis.

With $\alpha, \beta, S$ values known it is possible to calculate subsoil (Winkler) $K(x, y)$ distribution under SSS. The map of $K(x, y)$ isolines is shown below (Fig. 6).

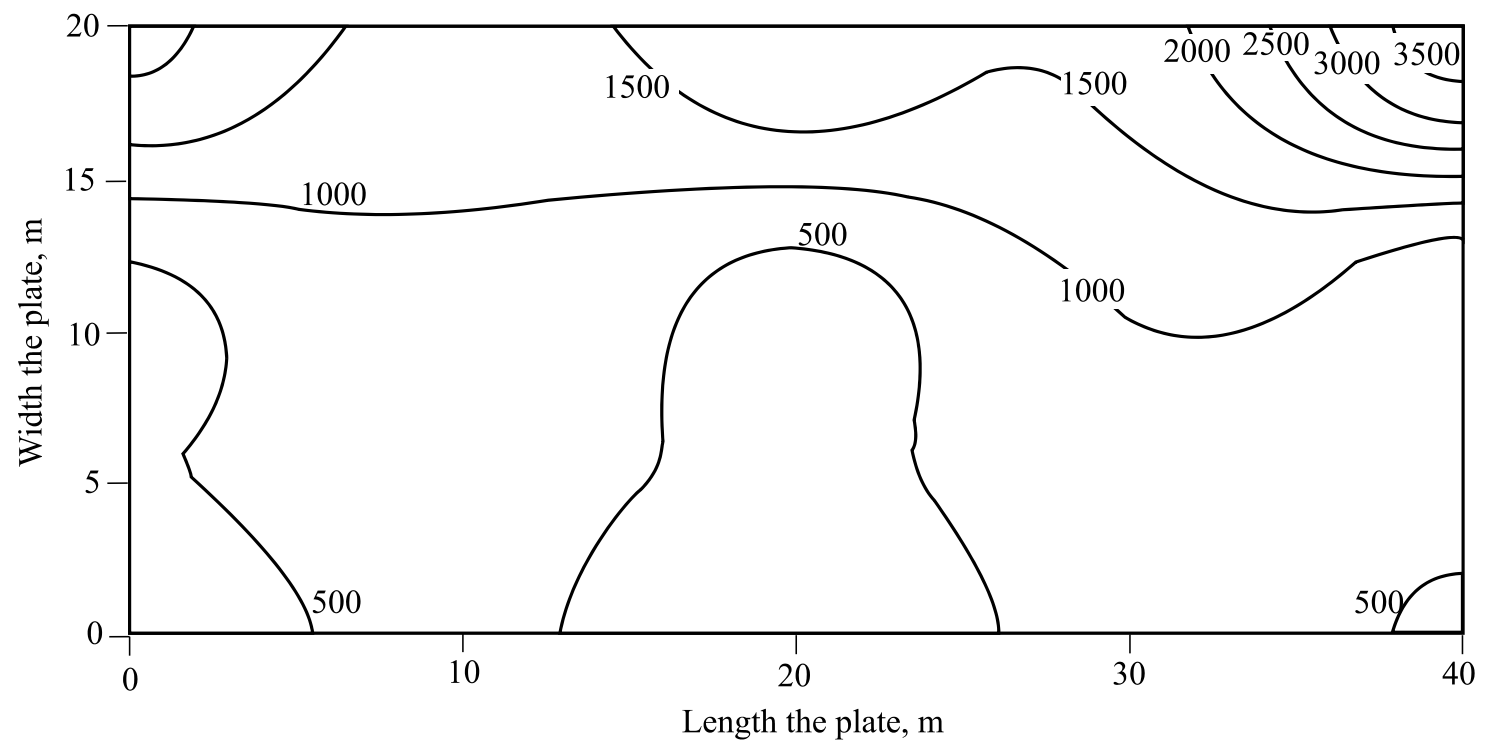

Figure 6: The map $K(x, y)$ isolines under SSS

\section{CONCLUSIONS}

SSS settlements analysis, based on a subsoil ratio concept, dates back to XVIII century and was firstly proposed by the great Swiss scientist Leonard Euler, then a Member of Russian Academy of Sciences in St. Petersburg. Later this subsoil ratio was renamed into Winkler parameter $\mathrm{K}=$ const. (Karl Winkler was also a Member Russian Academy of Sciences later in XIX century).

Ever since this method has been broadly applied thanks to its clarity and simplicity. It can also be applied to simulate any other subsoil models (elastic half-space, elastic layer, Pasternak model, etc.), non-homogeneous ones included, with the help of a method, proposed long ago (in 1869) by a German mathematician H.W. Schwartz [7]. It is an iterative procedure 
for solving the problem of two contacting elastic bodies, having different elastic parameters $\mathrm{E}_{1}, \mathrm{E}_{2}$ and $v_{1}, v_{2}$ respectively. Schwarz method is broadly applied in Russian for SSS interaction analysis. The Winkler (subgrade) model is broadly applied with $\mathrm{K} \neq$ const.

SSS simulation analysis can help assess the SSS sensitivity to various input data scatter and to multiple analytical hypotheses by numeric simulations (virtual monitoring) that will yield more data than any in situ (very costly and low informative) monitoring. It means that it is possible to solve geotechnical problems of soil-structure interaction with the help of simple methods right on the site during geotechnical survey with high accuracy and reliability.

\section{REFERENCES}

[1] K. Alshibi K., A.M. Okeil A.M., B. Alramahi. Update of correlations between cone penetration and boring log data. LTRC Report 439, 2008.

[2] K. Terzaghi, K. Theoretical Soil Mechanics, John Wiley \& Sons, New York., 1943.

[3] V.V. Sokolovsky. The statics of the granular medium, 1965.

[4] J. Boussinesq, J. Application des Potentiels á L'Étude de L’Équilibreet due Mouvement des Solides Élastiques, Gauthier-Villars, Paris, 1885.

[5] F. Schleicher. Zur Theorie des Baugrundes, Der Bauingenieur, 48, 1926.

[6] D.A. Shepard. A two-dimensional interpolation function for irregularly space data. Proceedings of the 23-th National conference of the Association for Computing Machinery (ACM). New York: ACM Press, 1968, 517-528.

[7] H.A. Schwartz. Uber einige Abbildungsaufgaben, Ges. Math. Abh., 1869,65-83. 